\title{
USING UNUSUAL TECHNOLOGIES COMBINATION FOR MADONNA STATUE REPLICATION
}

\author{
Bronislav KOSKA \\ Czech Technical University in Prague, Faculty of Civil Engineering \\ Thákurova 7, Prague 6, Czech Republic \\ bronislav.koska@fsv.cvut.cz
}

Keywords: laser scanning, computer tomography, CT, rapid prototyping, milling, NURBS

\begin{abstract}
An unusual combination of some modern technologies was used to create precise copy of a medieval lime Madonna with polychromy and the process is described in the paper. The used and combined technologies were computer tomography, 3D scanning and modeling with textures, rapid prototyping and 3D milling. These modern technologies are standardly used in relic documentation and restoration, but their combination in a synergic procedure is unique. The main reason for using them was owner demand for minimizing working time with the original statue that he needed it for exhibition. The time needed for working with the original statue was in the case about 20 percent of standard time and overall time needed for creation of copy was in the case about 40 percent of standard time.
\end{abstract}

\section{INTRODUCTION}

Madonna from Rouchovany was created about 1330. It represents an important medieval relic and it is part of the National Gallery archive. It is also the most significant relic of the city Rouchovany and that's why its councilmen decided to have its copy created and expose it to its original church. The National Gallery requested to release the statue from the exhibition for the shortest time possible and that's why the 3D scanning technologies and following were incorporated in the project. The statue shape is pretty complex from the 3D scanning point of view. Especially hollow back part presents an immense challenge see Figure 1. The problem of measuring for standard 3D scanner unreachable parts was solved by using computer tomography technology, which was also used for restoring exploration. 3D model was milled on 3D mill from lime wood to speed up copy creation process. 3D colour copy was also rapid prototyped in the 50 percent scale to help restorer with sculpting of details. The only part which had to be done side by side to the original statue was polychromy and patina coating.

\section{COMPUTER TOMGRAPHY}

The first applied technology is computer tomography (further called CT), which was used for two purposes. One of the purposes was restoring exploration of the statue condition and the second purpose was 3D measuring of surfaces unreachable by other technologies (hollow back part, long and narrow slots). The measurement was realised in the university hospital Motol by Mudr. J. Lisý during spare night hours on Siemens CT. The output of CT measuring was series of slides with resolution $512 \times 512$ (see Figure 2) and mutual distances one millimetre. The pixel size is about 1 $\mathrm{mm}(0.9765 \ldots)$ too. CT working box with defined accuracy is 500x500xheight millimetre what is slightly smaller than Madonna size. That is why it had to be scanned in two series. We got scanned data together with the freeware CT viewer $\mathrm{xVision}$, which can be also used to export slides to the standard CT format called "dicom" in version 3.0. 

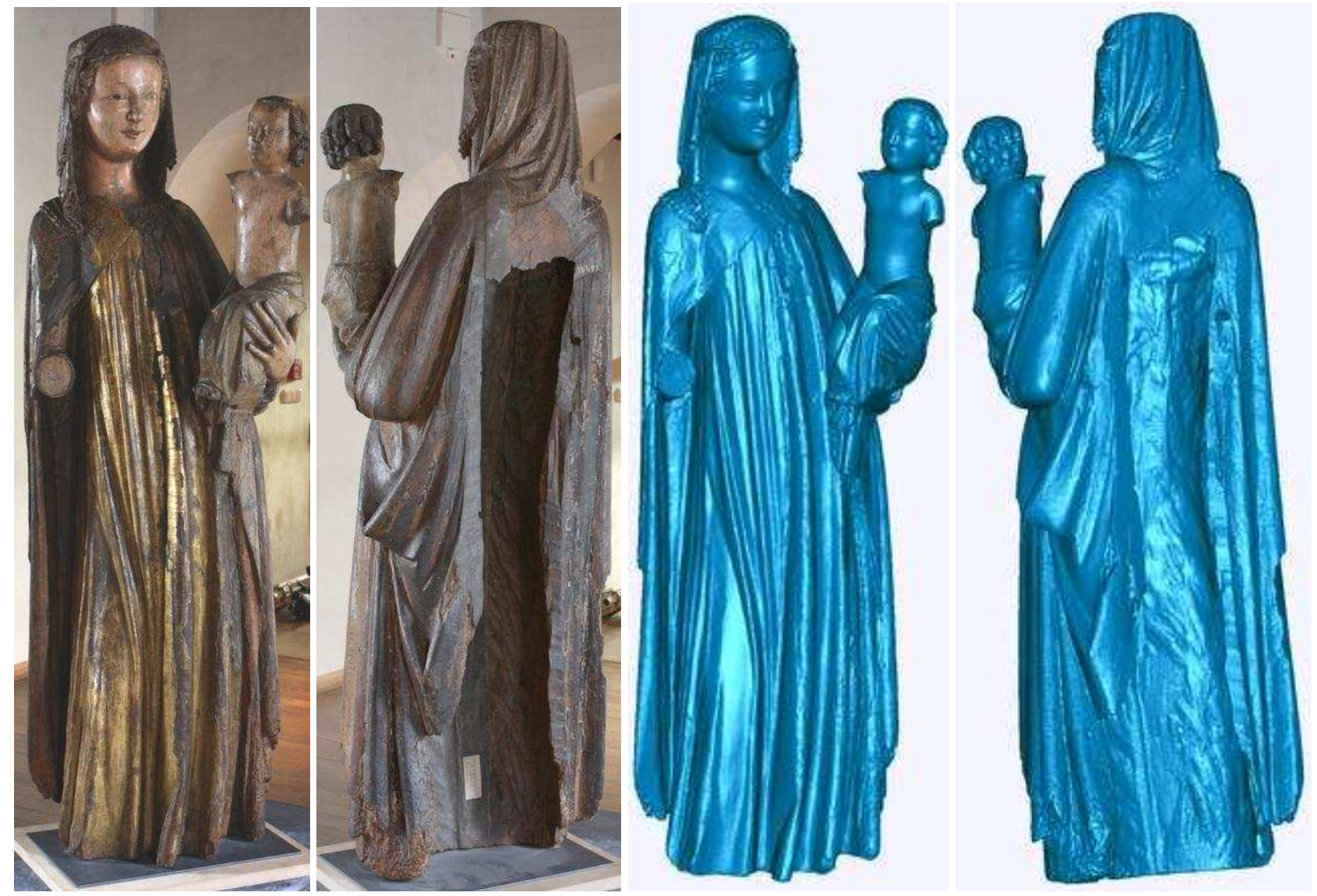

Figure 1: Madonna from Rouchovany, photograph and 3D model

There is a range of freeware/open source software for working with "dicom" image series available on the internet. We needed creation of triangulated surface (further called mesh) from the dicom series. The open source software DeVIDE $[1,2]$ seems to be suitable for the purpose. It has modular architecture, enables creation of schematic macro for automatic processing and it has a possibility to export 3D model to standard mesh format "stl".

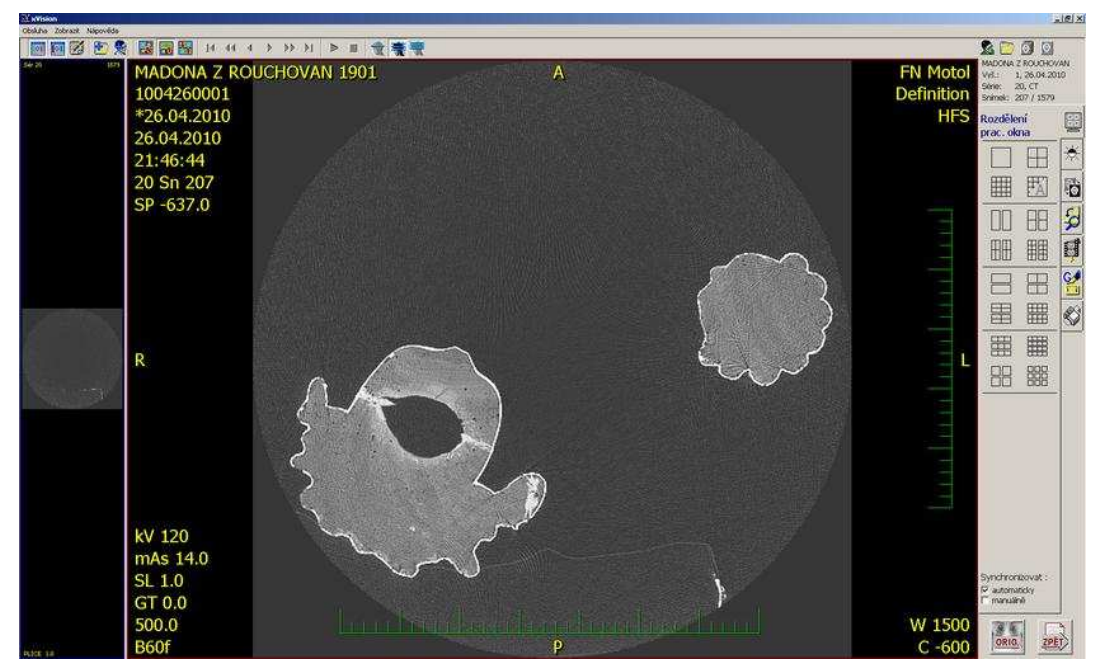

Figure 2: Example horizontal slide from CT in $\mathrm{xVision}$ software 

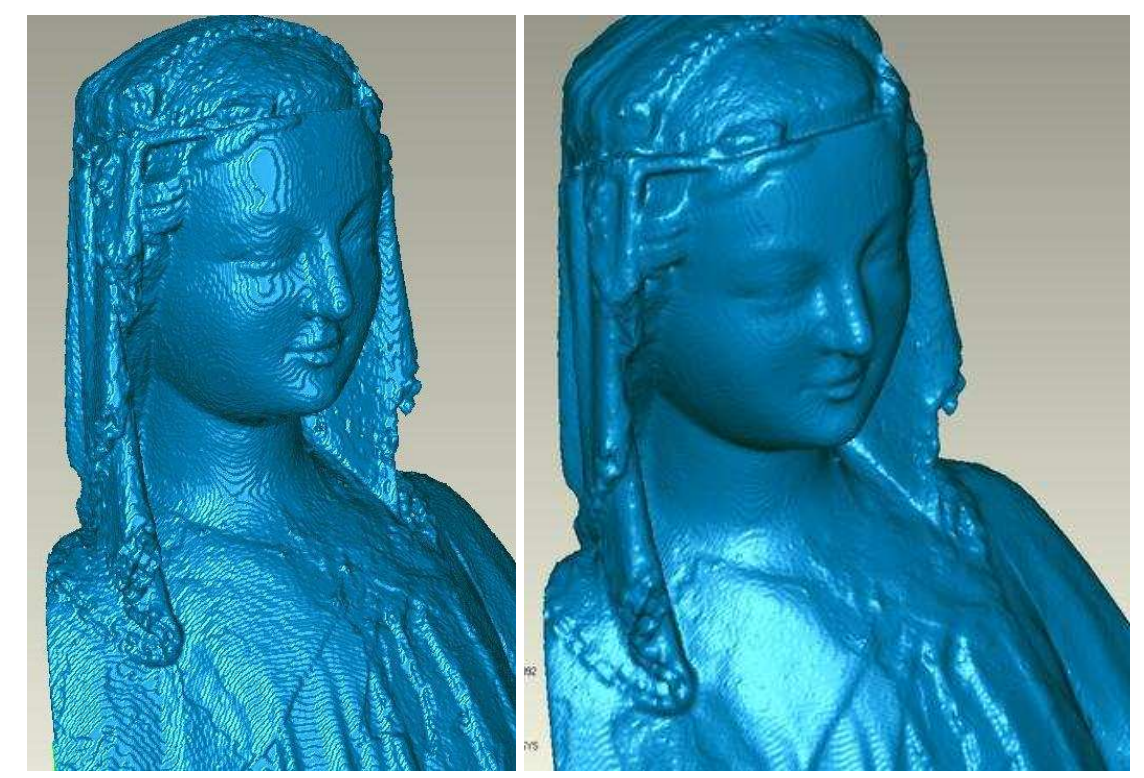

Figure 3: Model exported from the DeVIDE software and model after post processing in Geomagic Studio

The model created and exported from the DeVIDE software was pretty angular and was improved by post processing in the Geomagic Studio 11 software see Figure 3. It seems clear that 3D model based on the CT data isn't sufficient for a copy creation and supplement method had to be used.

\section{3D SCANNING - LORS}

As was stated before, the 3D model based on CT data was not sufficiently detailed. It was decided to do supplementing scanning using standard 3D scanner. Because of the statue size and instrument availability the self-developed laser scanning system LORS [3] was used.

The scanning takes two working days and was realized during closing days of National Gallery exhibition see Figure 4. 71 scan positions were accomplished without using control points. The scanning in each of six height level was realized in twelve position mutually rotated 30 degrees. The scanning resolution was set about $0.5 \mathrm{~mm}$ for the upper half part of the statue and about $1 \mathrm{~mm}$ for the lower part. All together about 40 millions points were measured. The main parameter of the scanning system LORS are stated in the Table 1.

\subsection{Modelling}

Registration was done sequentially using manual and global registration process in Geomagic Studio software. At first, each height level was registered independently. Then, all point clouds were reduced to the lower resolution $1 \mathrm{x} 1 \mathrm{~mm}$, because of too large amount of points to be worked with in the Geomagic Studio software. At the end of the registration process all height levels were globally registered together. There was about eight millions points and the global registration standard deviation from all 71 scan position was 0.8 millimetre. Meshing was realized in the open source software VripPack [4]. Surprisingly, this old opensource software give better results than Geomagic Studio in the case user has enough information about used scanning system and enough patience to learn how to control it. There was used voxel size $0.5 \mathrm{~mm}$ in the VripPack software. The 3D model covered more than 95 percent of statue surface, excluding unreachable hollow back part, which does not carry significant spatial or chromatic information. Surface missing in the data from the LORS scanning system was filled in using the CT mesh data see Figure 5. The final model is presented on the Figure 1 and a detail on the Figure 6. 


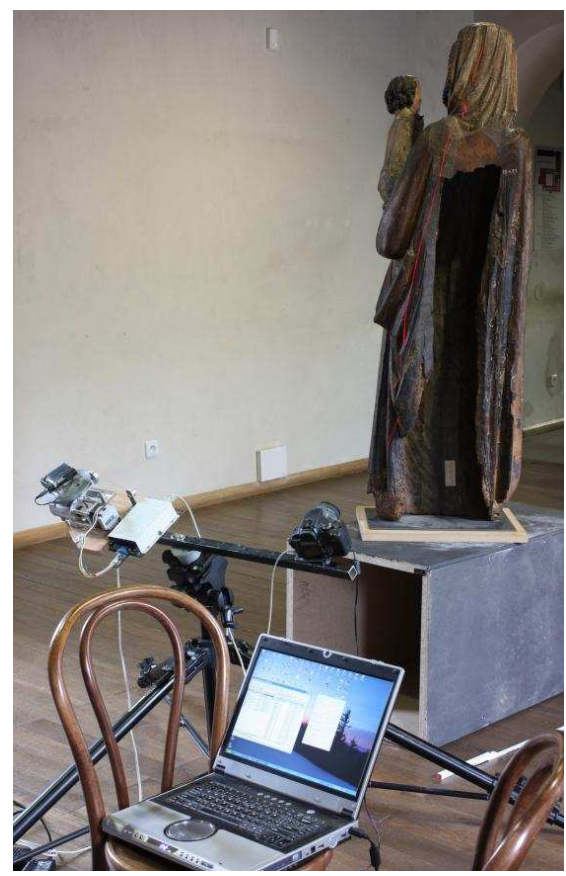

Figure 4: Scanning with the laser scanning system LORS

\section{Parameter}

Working range (width $\mathrm{x}$ height $\mathrm{x}$ depth) [meter]

Maximal resolution (horizontally x vertically)

Laser beam width [mm]

Accuracy $[\mathrm{mm}]$

Scanning rate

Size (width $\mathrm{x}$ height $\mathrm{x}$ depth) [meter]

Weight [kg]

\section{LORS}

$1.3 \times 0.9 \times 1.0$

$1950 \times 2304$

1

0.5

4.5 millions / 32 minutes

$1 \times 0.2 \times 0.2$

2

Table 1: Parameters of the laser scanning system LORS

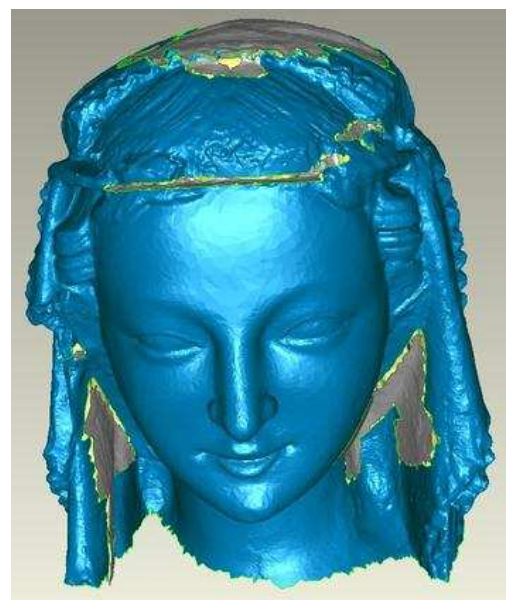

Figure 5: Surfaces filled in from the CT data (grey) to the LORS data (blue) in unreachable areas for LORS 

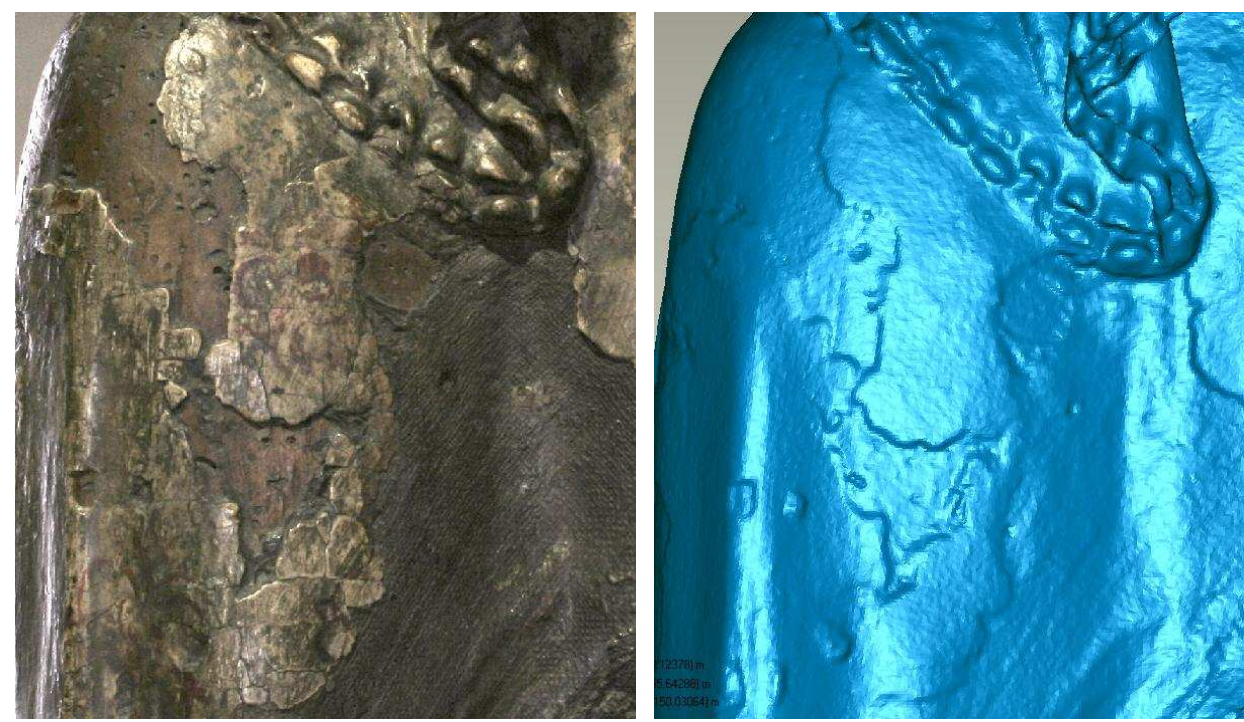

Figure 6: Photograph and the model of a detail (front view of left shoulder)

\section{RAPID PROTOTYPING}

3D colour copy was rapid prototyped in the 50 percent scale to help restorer with sculpting of details during the period he had not the original statue at disposal. Printing scale 50 percent was chosen because of the statue size and the parameters of used 3D printer Zprinter 450 which is located in the Laboratory of Photogrammetry (Faculty of Civil Engineering, CTU Prague) [5]. Statue wall-body was filled with empty shapes because of the expensiveness of printing material see Figure 7.

\subsection{Model partition}

The used Zprinter 450 has printing box size $203 \times 254 \times 203$ millimeters [5] and that's why the model had to be divided into five parts. Surface of the parts had to be closed and supplemented with connection elements, which were realized by column shape holes with diameter 3 and depth 10 millimeters see Figure 7 on the left.
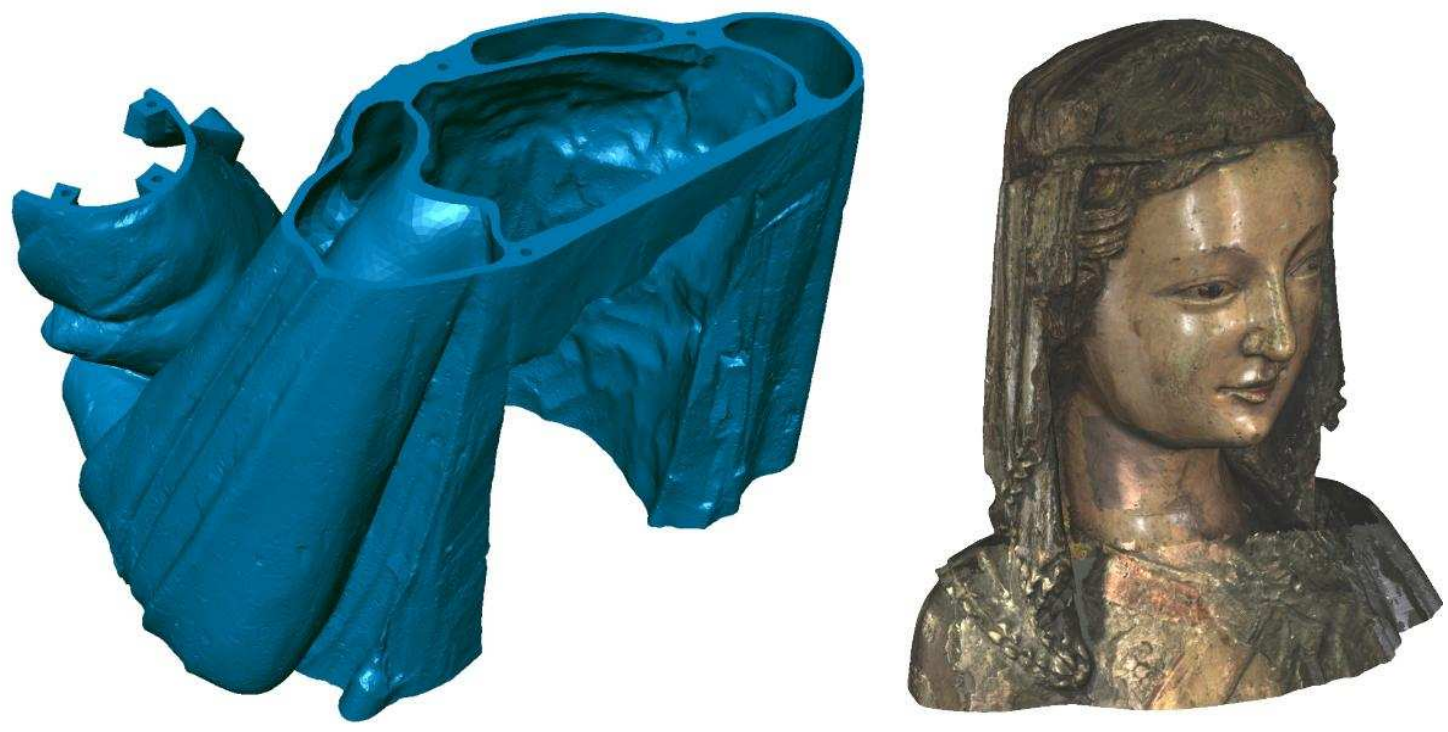

Figure 7: Two parts prepared for rapid prototyping (cuts, hollow spaces, connection parts) 


\subsection{Texture mapping}

Texture was also applied to the model for better orientation of the restorer and chromatic information presentation. A self-developed software was used for texture mapping, because the inner and outer orientation for texture images was precisely known from the scanning system LORS. The software is called Precise Texture Mapping [6] and enables some basic texture-balancing see Figure 7 on the right. The final printed model can be seen on the Figure 8 .

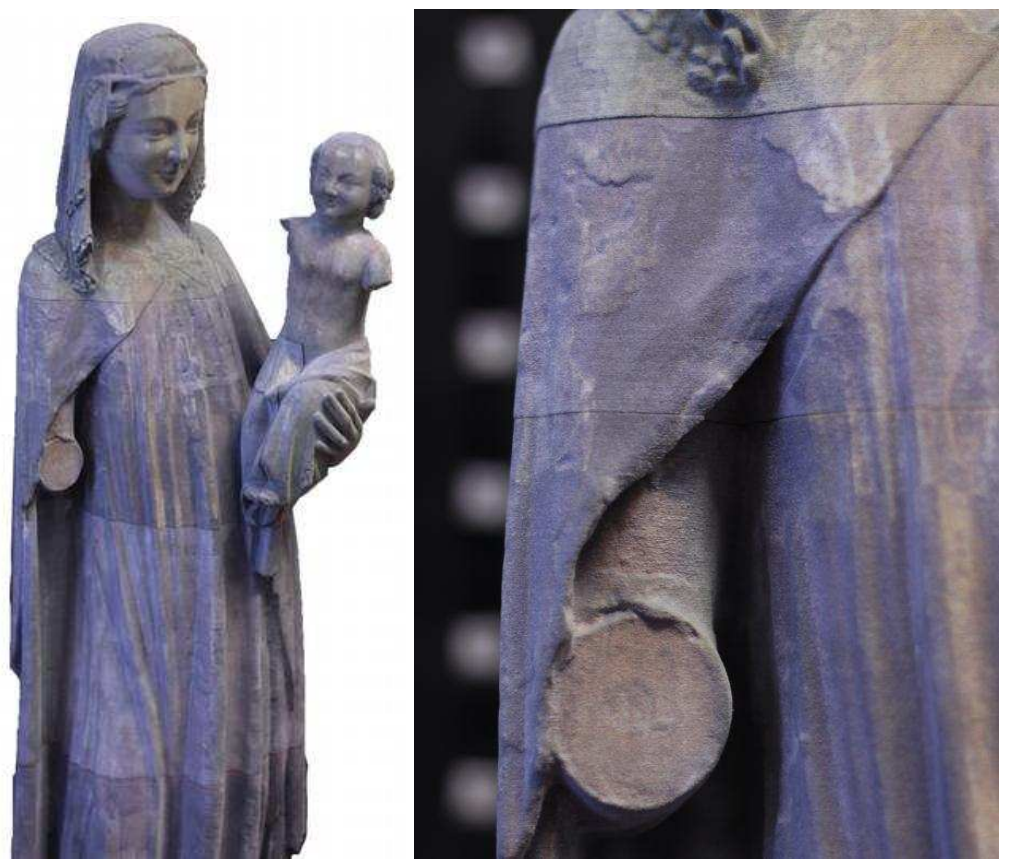

\section{3D MILLING}

Figure 8: 3D printer result

It was decided to use 3D milling cutter - CNC to speed up realization of the copy. File formats for description of socalled free-form shapes are based on NURBS (Non-Uniform Rational B-Spline) representation in the field of mechanical engineering. So far, in the project used formats were based on Triangulated Irregular Networks also called mesh. The character of two mentioned formats (mesh and NURBS) is fundamentally different and therefore there is no possibility of fully automatic conversion. A NURBS model does not seem to preserve so much detail as a mesh model at least during automatic conversion. The mesh model was enlarged 1 millimeter in the normal direction to keep rather more material than less in details. Valid NURBS model was created using automatic process in the Geomagic Studio software and was manually edited. The NURBS model quality was checked using 3D Compare tool in the Geomagic Studio. There were only very small and rather complicated and angular areas where the NURBS model was smaller than the mesh model see yellow areas on the Figure 9.

\section{RESULT}

Only the last replication step had to be realized using the original statue at the client place. It represents final surface brushing up, polychromy and patina coating. It took only a few weeks instead of few months usually needed. Result is displayed on the Figure 11.

\section{SUMMARY}

The paper describes a unique procedure of medieval Madonna copy creation. The main advantages of suggested procedure is significantly shorter time needed for working with the original statue (in the case about 20 percent of standard time) and considerably shorter overall time for creation of copy (in the case 30-40 percent of standard time). The procedure incorporates a range of relatively modern technologies and their synergic combination. It includes computer tomography, 3D scanning and modeling with textures, rapid prototyping and 3D milling. The realized project proofed applicability of the procedure and shown its advantages, but also revealed its most problematic parts. 


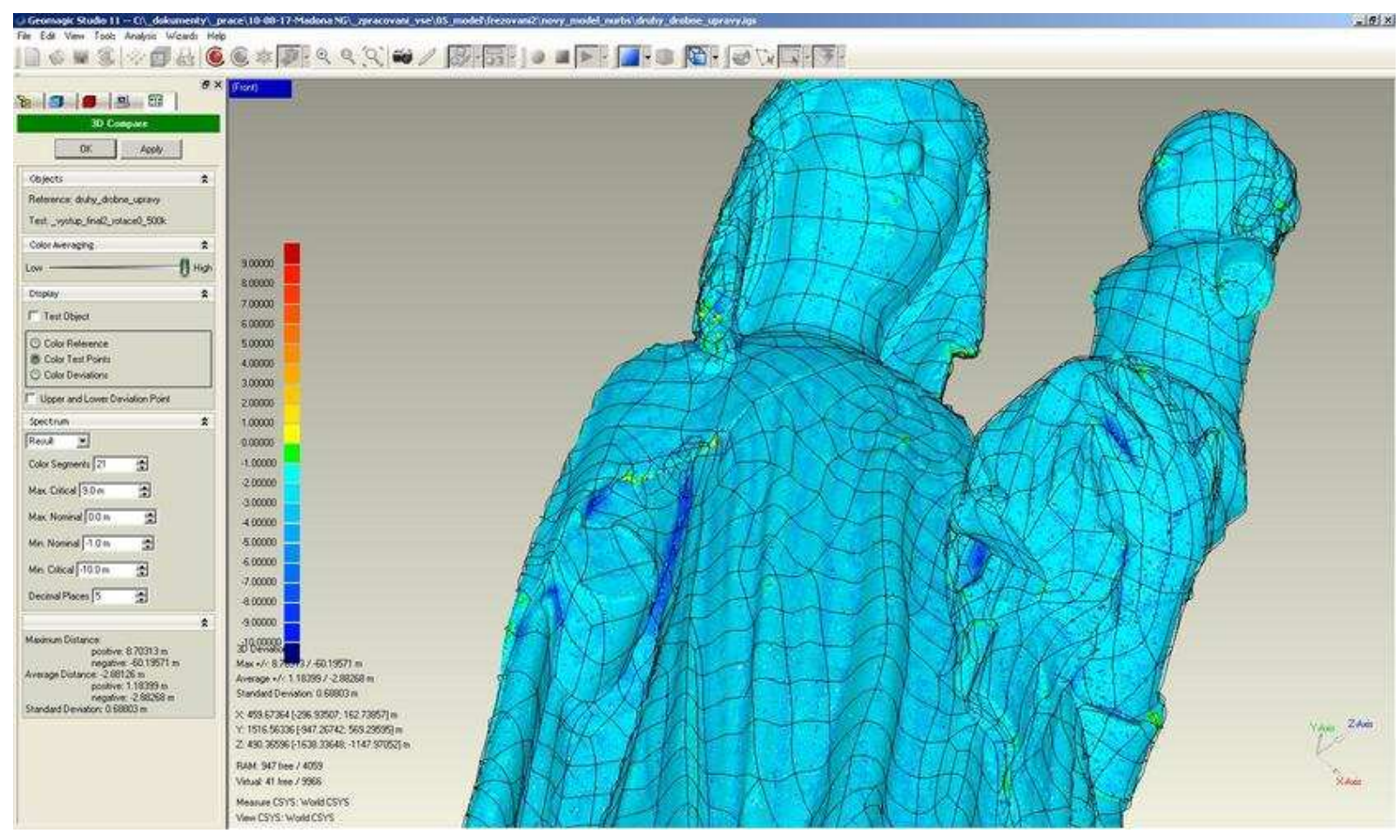

Figure 9: Differences between NURBS and mesh model

Realization of the statue copy using 3D milling cutter is shown on the Figure 10.

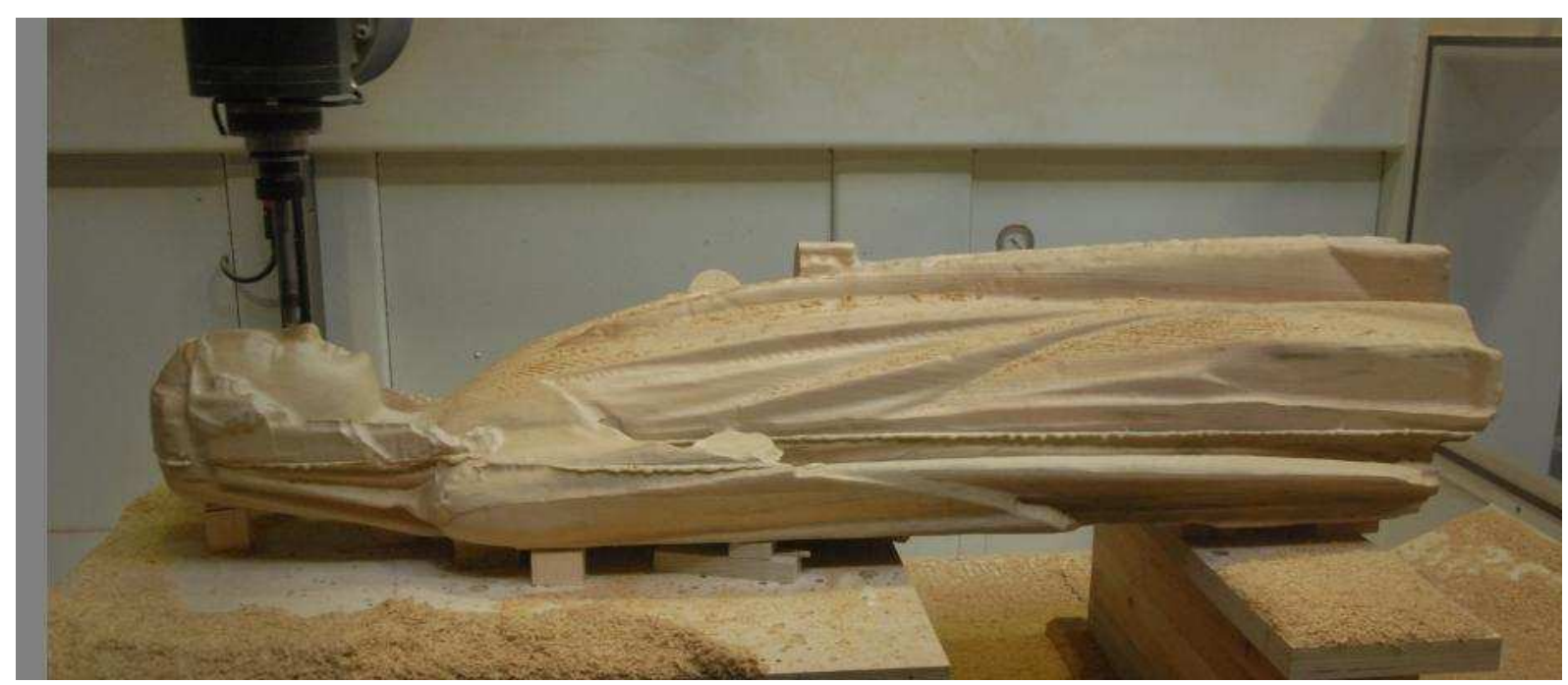

Figure 10: 3D milling cutting - CNC

\section{ACKNOWLEDGEMENTS}

This research has been supported by grant SGS11/046/OHK1/1T/11.

Restorer refined the cut model according to rapid prototyped model in his studio. 


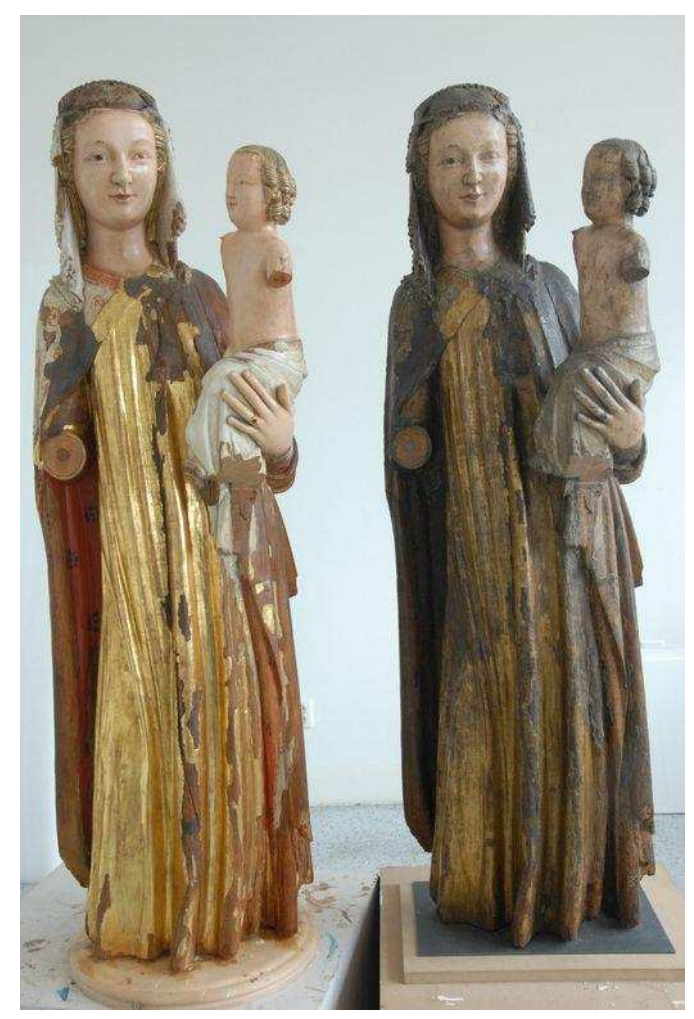

Figure 11: Side by side photograph of the copy and the original statue

\section{REFERENCES}

[1] TU Delft Graphics Group [online]. 2008 [cit. 2011-06-05]. Project DeVIDE. Available on WWW:

〈http://graphics.tudelft.nl/Projects/DeVIDE>.

[2] Pavelka, K., Dolanský, T.: Using of Non-expensive 3D Scanning Instruments for Cultural Heritage Documentation. CIPA Symposium WG6. Antalya, ISPRS, 2003, vol. 1, p. 158-162. ISSN 1682-1777.

[3] Botha, C. P., Post, F. H.: Hybrid scheduling in the DeVIDE dataflow visualisation environment, Proceedings of Simulation and Visualization (H. Hauser, S. Strassburger, and H. Theisel, eds.) , pp. 309-322, SCS Publishing House Erlangen, February 2008.

[4] Koska, B., Pospíšil, J., Štroner, M.: Innovations in the Development of Laser and Optic Rotating scanner LORS, XXIII International FIG Congress, Munich, Germany, ISBN 87-90907-52-3, 2006. Available on WWW: < http://k154.fsv.cvut.cz/ koska/publikace/publikace_en.php>

[5] Curless, B., Levoy, M.: A volumetric method for building complex models from range images, SIGGRAPH `96, New Orleans, LA, 4-9 August 1996. Available online:

$\langle$ http://www.cs. washington.edu/homes/curless/>

[6] ZCORPORATION [online]. [cit. 2011-06-05]. ZPrinter 450. Available online:

$<$ http://www.zcorp.com/en/Products/3D-Printers/ZPrinter-450/spage.aspx>.

[7] Koska, B.: Precise Texture Mapping. [online]. 2010 [cit. 2011-04-30]. Available online:

$\langle$ http://k154.fsv.cvut.cz/ koska/software/ptm/ptm.php>.

[8] Pavelka, K. - Řezníček, J. Low-cost Culture Heritage Documentation and Preservation Using Optical Correlation Scanner (OCS). Proceedings of 22th CIPA Symposium [CD-ROM]. Kyoto, ISPRS, 2009, vol. 1, p. 125-132.

[9] Pavelka,K.: Using of Non-expensive 3D Scanning Instruments for Cultural Heritage Documentation, CIPA Symposium WG6, Korfu, 2002, pp-59-68

[10] Koska, B. - Pospíšil, J. - Štroner, M. The Result Presentation of the Development of Laser and Optic Rotating Scanner LORS and Introduction of Public Library of Classes and Functions SPATFIG . Optical 3-D Measurement Techniques VII, Volume I. Vienna: TU Vienna, 2005, vol. 1, p. 63-73. ISBN 3-9501492-2-8. 